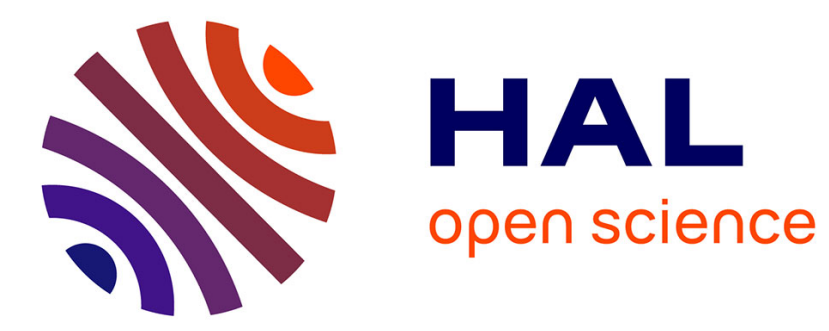

\title{
Fully quantum self-consistent study of ultimate DG-MOSFETs including realistic scattering using a Wigner Monte-Carlo approach
}

\author{
D. Querlioz, J. Saint-Martin, V.-N. Do, A. Bournel, P. Dollfus
}

\section{> To cite this version:}

D. Querlioz, J. Saint-Martin, V.-N. Do, A. Bournel, P. Dollfus. Fully quantum self-consistent study of ultimate DG-MOSFETs including realistic scattering using a Wigner Monte-Carlo approach. 2006 International Electron Devices Meeting, Dec 2006, San Francisco, United States. 10.1109/IEDM.2006.346939 . hal-01827054

\section{HAL Id: hal-01827054 \\ https://hal.science/hal-01827054}

Submitted on 1 Jul 2018

HAL is a multi-disciplinary open access archive for the deposit and dissemination of scientific research documents, whether they are published or not. The documents may come from teaching and research institutions in France or abroad, or from public or private research centers.
L'archive ouverte pluridisciplinaire HAL, est destinée au dépôt et à la diffusion de documents scientifiques de niveau recherche, publiés ou non, émanant des établissements d'enseignement et de recherche français ou étrangers, des laboratoires publics ou privés. 


\title{
Fully quantum self-consistent study of ultimate DG-MOSFETs including realistic scattering using a Wigner Monte-Carlo approach
}

\author{
D. Querlioz, J. Saint-Martin, V.-N. Do, A. Bournel and P. Dollfus \\ Institut d'Electronique Fondamentale, UMR 8622, CNRS, Univ. Paris Sud, 91405 Orsay cedex, France
}

\begin{abstract}
A new self-consistent quantum simulator based on the Monte Carlo solution of Wigner transport equation is used to analyze the operation of $6 \mathrm{~nm}$-long DG-MOSFETs. By comparison with other simulation approaches, the work emphasizes the important role of scattering and quantum effects on the electrical characteristics of such nano-devices. The results are confronted to ITRS specifications and the various effects of aggressive oxide thickness thinning on device performance are discussed.
\end{abstract}

\section{Introduction}

To capture the physics occurring in nano-scaled devices, we have developed a fully quantum simulator based on the Wigner formalism. Using this new tool, this work analyzes the performance of ultra-short DG-MOSFETs. The study emphasizes the importance of scattering and of quantum effects on the device operation and electrical characteristics regarding ITRS requirements for the HP $16 \mathrm{~nm}$ node (1).

The simulator is based on the Wigner Transport Equation (WTE) which is solved in the mode-space approximation. This approach is fully self-consistent and includes all relevant scattering mechanisms as accurately as in standard Ensemble Monte Carlo (EMC) simulation. Our particle technique to solving the Wigner transport equations is inspired by an approach suggested by Shifren et al (2), with some major improvements on the particle injection technique $(3,4)$, which allows us to accurately describe the quantum transport effects, as shown by simulation of RTDs (3). Compared to the technique of Ref. $(5,6)$ this one can be implemented into selfconsistent EMC simulation. In comparison with direct Schrödinger's equation (7) or the well-known non-equilibrium Green's function (NEGF) approach (8-12), this Wigner EMC technique offers the advantage of taking easily into account all scattering mechanisms (phonons, impurity, surface roughness) and of being naturally a time simulation of quantum transport which may include transient effects.

\section{Presentation of the model}

This work presents the first self-consistent simulation of MOSFET using a particle description of quantum transport based on the Wigner function (13).
In this formalism, for each confined sub-band of the device $E_{\mathrm{n}}(x)$, the Wigner function $f_{w}(x, k)$ evolves according to

$\frac{\partial f_{w}}{\partial t}+\frac{\hbar k}{m} \frac{\partial f_{w}}{\partial x}=Q f_{w}+C f_{w}$

where the quantum evolution term of the Wigner function is given by

$Q f_{w}(x, k)=\frac{1}{(2 \pi)} \int d k^{\prime} V_{w}\left(x, k-k^{\prime}\right) f_{w}\left(x, k^{\prime}\right)$.

The Wigner potential $V_{w}(x, k)$ is defined by

$V_{w}(x, k)=\int d x^{\prime} \sin \left(k x^{\prime}\right)\left[E_{n}\left(x+\frac{x^{\prime}}{2}\right)-E_{n}\left(x-\frac{x^{\prime}}{2}\right)\right]$

and $C f_{w}$ is the collision term with $2 \mathrm{DEG}$ scattering rates.

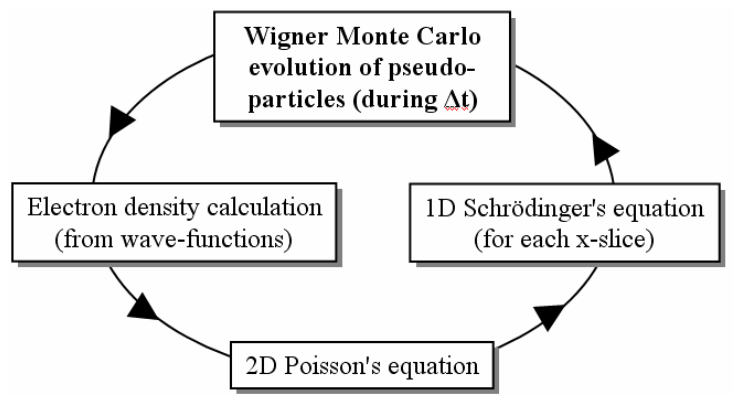

Fig. 1. MC Algorithm used for the Wigner simulation

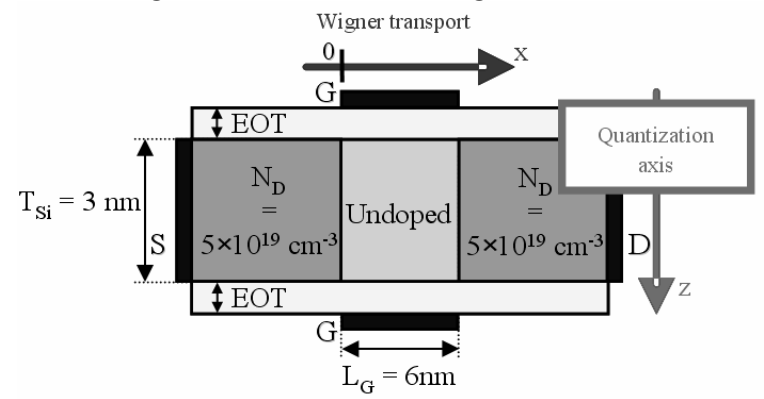

Fig. 2. Simulated DG-MOSFET structure. EOT is $1.0 \mathrm{~nm}$ or $0.5 \mathrm{~nm}$. The highly-doped S/D regions are $15 \mathrm{~nm}$-long.

In this technique, we consider the Wigner function $f_{w}$ as a sum of pseudo-particles localized in both $x$ and $k$ space weighted by a parameter called affinity (2) that contains the quantum information on the particles. The $x$ and $k$ coordinates evolve exactly as that of classical particles, while the affinity is updated according to the $Q f_{\mathrm{w}}$ term of the WTE. Scatterings are included 
using the standard MC algorithm (Figs. 1-2), by making use of 2DEG scattering rates. The calculation of these inter and intra sub-band scattering rates is described in (14), and is similar to $(15,16)$. The simulated device is meshed into vertical slices in which the 1D Schrödinger equation is solved to compute the subband profiles $E_{\mathrm{n}}(x)$ and wave-functions $\xi_{n}$ (14).

\section{Simulation results on ITRS $16 \mathrm{~nm}$ devices}

\section{A. Electrical results}

We have studied two $6 \mathrm{~nm}$-long DG-MOSFETs (described in Fig. 2), differing in their gate equivalent oxide thickness (EOT). Unless otherwise stated the gate work function is assumed to be that of a midgap gate minus $0.2 \mathrm{eV}$. Figs. $3 \mathrm{a}$ and $3 \mathrm{~b}$ show typical density and potential mappings and exhibit oxide repulsion typical of quantization effects. Subband profiles are plotted in Fig. 4, together with cartographies of the squared wave function of each type of subbands considered in the simulation.
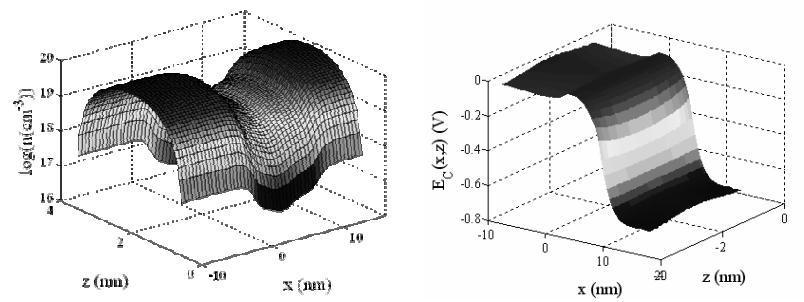

Fig. 3. a)Electron density $n(x, z)$ at $V_{\mathrm{GS}}=0.45 \mathrm{~V}$ and $V_{\mathrm{DS}}=0.7 \mathrm{~V}$ b) Bottom of conduction band $E_{\mathrm{C}}(x, z)$
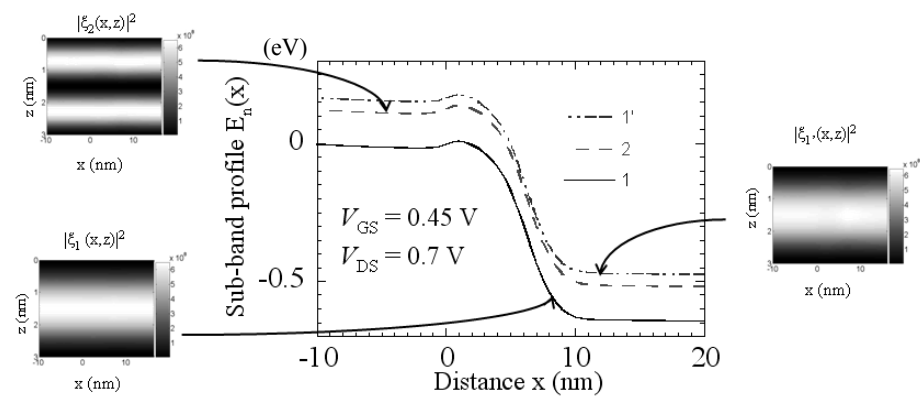

Fig. 4. Sub-band profiles and cartography of the squared wave-functions associated with the sub-bands. EOT is $1 \mathrm{~nm}$.

Figs. 5, 6 and 7 show the I-V characteristics obtained for EOT $=1 \mathrm{~nm}$. They are compared with that obtained from semi-classical Boltzmann MC simulation including multisubband description (14) (dashed lines) and from ballistic NEGF simulation (17) (dotted lines).

In subthreshold regime the Wigner results are very close to quantum ballistic ones but the current is significantly higher than that obtained using semi-classical simulation. This shows that scattering has a weak impact in this regime but that $I_{\text {off }}$ is strongly enhanced by S-D tunneling through the channel barrier.

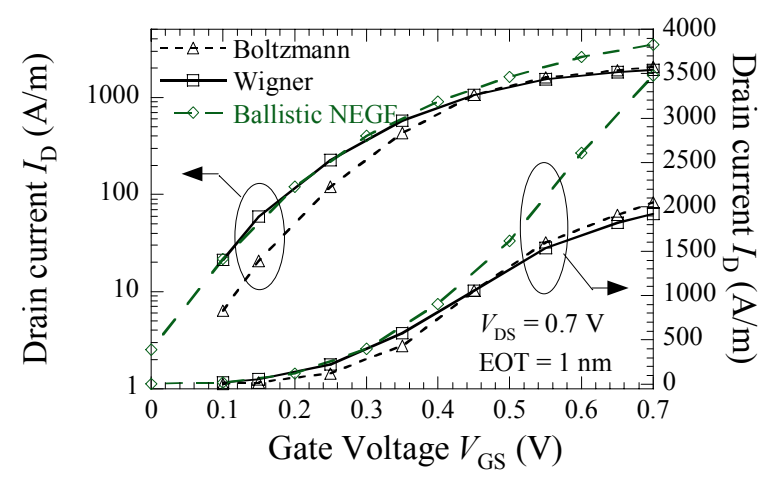

Fig. 5. Logarithmic and linear plots of the drain current $I_{\mathrm{D}}$ versus $V_{\mathrm{GS}}$ using Wigner, Boltzmann and ballistic NEGF simulations, at high $V_{\mathrm{DS}}$.

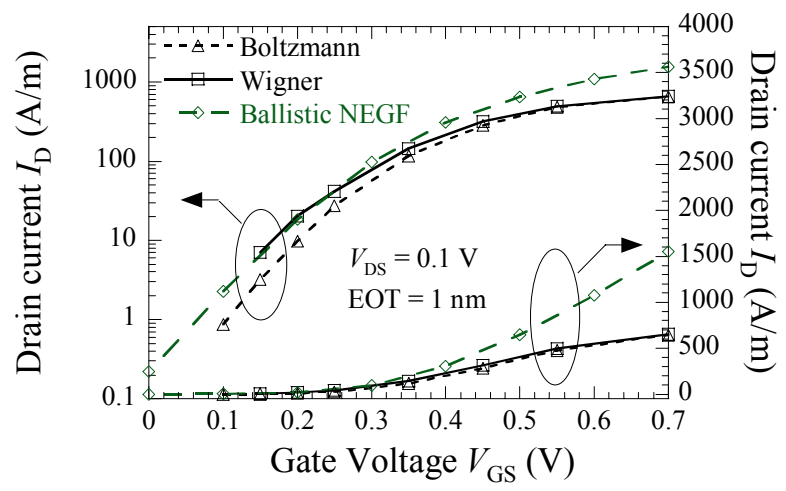

Fig. 6. $I_{\mathrm{D}}$ versus $V_{\mathrm{GS}}$ at low $V_{\mathrm{DS}}$ in log and linear scales.

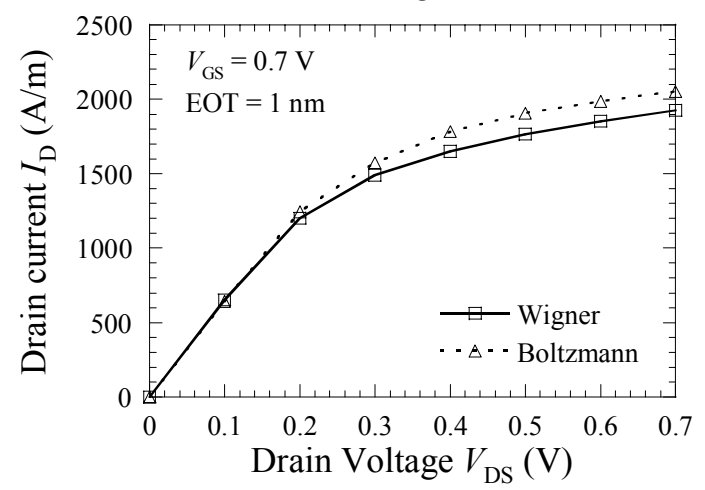

Fig. 7. Drain current $I_{\mathrm{D}}$ versus $V_{\mathrm{DS}}$ using Wigner and Boltzmann models.

In contrast, the ballistic approach strongly overestimates the $I_{\text {on }}$ current due to the significant influence of scattering in both the channel and the highly doped access regions (18). As shown in Fig. 7, the drain current in saturation regime is perceptibly reduced by including quantum transport effects, which suggests the arising of quantum reflections in the channel under high drain bias as a consequence of the steep potential drop (4). 


\section{B. Discussion on the impact of scattering in the channel}

The effect of scattering in the channel is well illustrated in Fig. 8 where we compare the results of Wigner simulation using standard scattering rates (solid lines) with that obtained by switching the scattering mechanisms off in the channel (dashed lines). An effective ballisticity $B_{\text {eff }}=I_{\text {on }} / I_{\text {onball }}$ of $86 \%$ is obtained as a result of an $I_{\text {on }}$ enhancement by $16 \%$ in the case with no scattering in the channel.

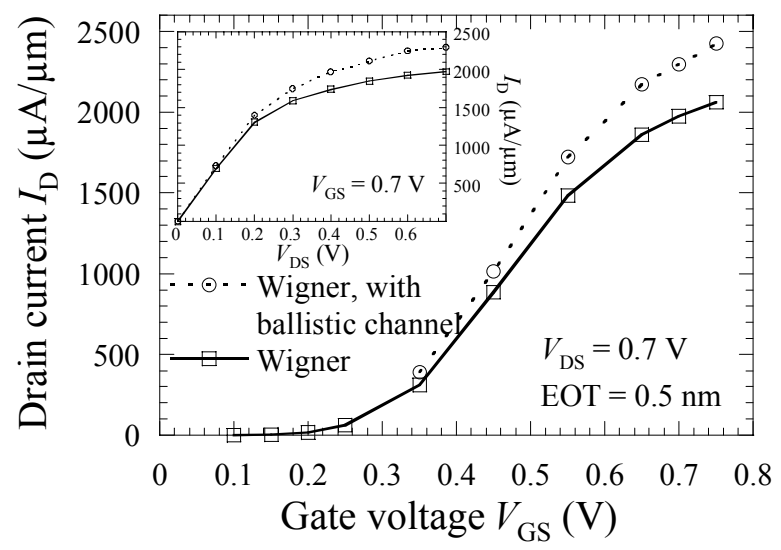

Fig. 8. $I_{\mathrm{D}}\left(V_{\mathrm{GS}}\right)$ for high $V_{\mathrm{DS}}$, with and without scattering in the channel. Inset: $I_{\mathrm{D}}\left(V_{\mathrm{DS}}\right)$ for high $V_{\mathrm{GS}}$, with and without scattering in the channel

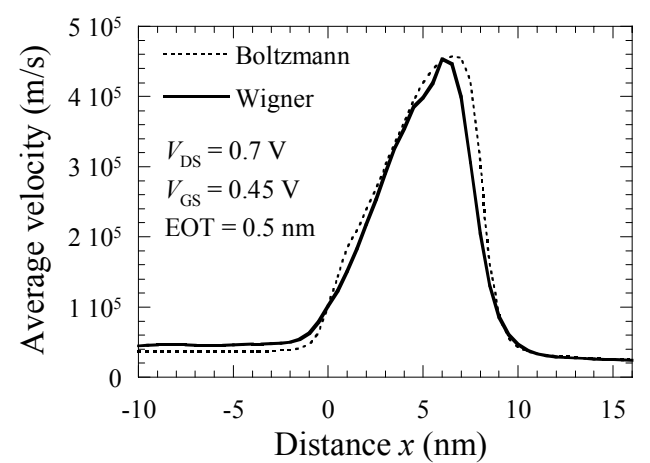

Fig. 9. Average electron velocity along the device using Wigner and Boltzmann simulations.

The electron velocity profile along the channel is plotted in Fig. 9 in both cases of Wigner and Boltzmann transport simulations. Results are very similar in both cases. As a consequence of high ballisticity, they exhibit a strong overshoot velocity of $4.5 \times 10^{7} \mathrm{~cm} / \mathrm{s}$ near the drain-end of the channel. The distribution of scattering mechanisms occurring at different positions in the channel is displayed in Fig. 10. As a consequence of carrier heating, the relative contribution of intervalley scattering increases near the drain. The part of roughness scattering decreases near the drain-end. However this diffusion mechanism remains predominant in this ultra-thin body device.

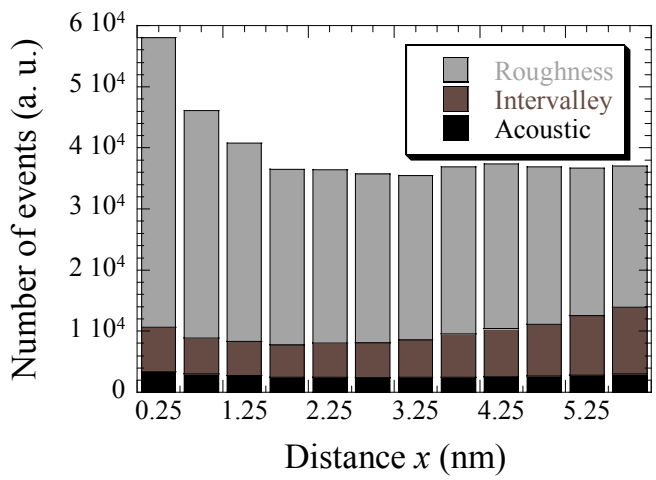

Fig. 10. Distribution of scattering events along the channel

\section{Discussion on electrical performance}

Using these three simulation approaches, the intrinsic delay $C_{\mathrm{G}} V_{\mathrm{DD}} / I_{\text {on }}$ is estimated in Fig. 11 as a function of $I_{\text {off }}$, for different gate work functions $\Phi$. Whatever $\Phi$ and the model used, the delay cannot meet the ITRS specifications, even using ballistic NEGF that overestimates $I_{\text {on }}$. Moreover the $I_{\text {off }}$ values obtained for EOT $=1 \mathrm{~nm}$ are quite high regarding ITRS target.

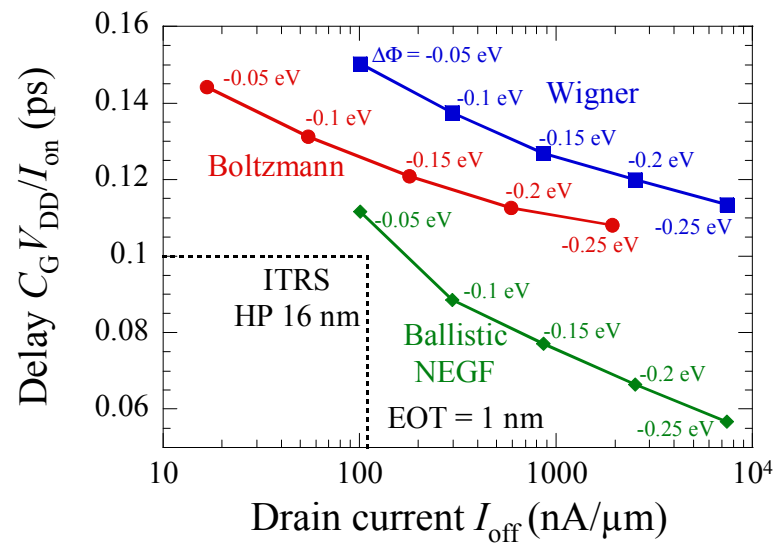

Fig. 11. $C_{\mathrm{G}} V_{\mathrm{DD}} / I_{\mathrm{on}}\left(I_{\mathrm{off}}\right)$ for various gate workfunctions (indicated through the difference $\Delta \Phi$ with a midgap gate).

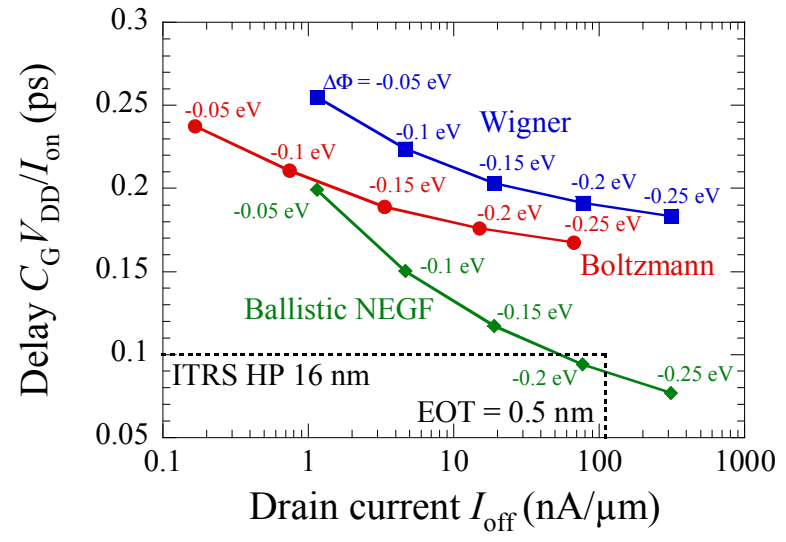

Fig. 12. Intrinsic gate delay $C_{\mathrm{G}} V_{\mathrm{DD}} / I_{\text {on }}$ as a function of $I_{\text {off }}$ for DG with $\mathrm{EOT}=0.5 \mathrm{~nm}$. 
More surprisingly, for an EOT of $0.5 \mathrm{~nm}$ (recommended by ITRS), ITRS targets are not fully reached. The main electrical characteristics obtained for both devices using Wigner simulation are summarized in Table I and compared with some ITRS specifications for HP $16 \mathrm{~nm}$ node.

The EOT thinning reduces significantly $I_{\text {off }}$, which appears on the delay- $I_{\text {off }}$ plot of Fig. 12. However, the resulting enhancement of gate capacitance does not allow the device to meet the ITRS requirements regarding the delay. The $\mathrm{I}_{\text {on }}$ improvement is actually limited because of high access resistance in the narrow source and drain. Novel technological advances with reduced access resistances, e.g. metallic source/drain, might be required to reach these objectives.

As a consequence of this limited $\mathrm{I}_{\mathrm{on}}$ improvement and because of gate capacitance enhancement, oxide thinning does not provide any benefit in terms of delay. For the same $I_{\text {off }}$, the delay is actually more important for a $0.5 \mathrm{~nm}$ EOT than for a $1.0 \mathrm{~nm}$ EOT. For $I_{\text {off }}=0.11 \mu \mathrm{A} / \mu \mathrm{m}$, the delay is $0.15 \mathrm{ps}$ for an EOT of $1 \mathrm{~nm}$ and $0.19 \mathrm{ps}$ for an EOT of $0.5 \mathrm{~nm}$.

\section{Conclusion}

Thanks to a powerful new quantum simulator, this work shows the difficulty to meet ITRS specifications for the HP $16 \mathrm{~nm}$ node due to the importance of both scattering and quantum effects in ultimate DG-MOSFET. Additionally, it is shown that for this aggressive nanoscale design, reducing the EOT from $1 \mathrm{~nm}$ to $0.5 \mathrm{~nm}$ can be detrimental to the delay CV/I.

TABLE I

COMPARISON OF PARAMETERS EXTRACTED FROM WIGNER SIMULATION WITH ITRS SPECIFICATIONS

\begin{tabular}{cccc}
\hline & EOT=10 & EOT=5 $($ ITRS) & ITRS $16 \mathrm{~nm}$ \\
\hline$S(\mathrm{mV} / \mathrm{dec})$ & 110 & 90 & $<100$ \\
$\mathrm{DIBL}(\mathrm{mV})$ & 107 & 55 & - \\
$B_{\mathrm{eff}}$ & $85 \%$ & $86 \%$ & - \\
$I_{\mathrm{ON}}(\mu \mathrm{A} / \mu \mathrm{m})$ & 1920 & 1975 & 2744 \\
$I_{\mathrm{OFF}}(\mu \mathrm{A} / \mu \mathrm{m})$ & 2.5 & 0.077 & 0.11 \\
$C_{\mathrm{G}}(\mathrm{fF} / \mu \mathrm{m})$ & 0.33 & 0.54 & 0.41 \\
$C_{\mathrm{G}} V_{\mathrm{DD}} / I_{\mathrm{ON}}(\mathrm{ps})$ & 0.12 & 0.19 & 0.10 \\
\hline$I_{\mathrm{ON}}(\mu \mathrm{A} / \mu \mathrm{m})$ for & 1540 & 1980 & 2744 \\
$I_{\mathrm{OFF}}=0.11 \mu \mathrm{A} / \mu \mathrm{m}$ & & & \\
$C_{\mathrm{G}} V_{\mathrm{DD}} / I_{\mathrm{ON}}$ for & 0.15 & 0.19 & 0.10 \\
$I_{\mathrm{OFF}}=0.11 \mu \mathrm{A} / \mu \mathrm{m}$ & & & \\
\hline
\end{tabular}

\section{Acknowledgments}

This work was partially supported by the European Community 6th FP, through NoE SINANO (IST 506844) and IP PULLNANO (IST 4-026828), and by the French ANR, through project MODERN.

\section{References}

(1) ITRS, http://public.itrs.net/

(2) L. Shifren, C. Ringhofer, and D. K. Ferry, "A Wigner function-based quantum ensemble Monte Carlo study of a resonant tunneling diode," IEEE Trans. Electron Devices, vol. 50, pp. 769-773, 2003.

(3) D. Querlioz, P. Dollfus, V.-N. Do, and V. Lien Nguyen, "An Improved Wigner Monte-Carlo Technique for the self-consistent Simulation of RTDs," in Proc. IWCE 2006, J. Comput. Elec., in press.

(4) D. Querlioz, J. Saint-Martin, V.-N. Do, A. Bournel, and P. Dollfus, "A study of quantum transport in end-of-roadmap DG-MOSFETs using a fully self-consistent Wigner Monte Carlo approach," IEEE Trans. Nanotechnology, in press, 2006.

(5) V. Sverdlov, A. Gehring, H. Kosina, and S. Selberherr, "Quantum transport in ultra-scaled double-gate MOSFETs: A Wigner functionbased Monte Carlo approach," Solid-State Electronics, vol. 49, pp. 1510-1515, 2005.

(6) M. Nedjalkov, H. Kosina, S. Selberherr, C. Ringhofer, and D. K. Ferry, "Unified particle approach to Wigner-Boltzmann transport in small semiconductor devices," Phys. Rev. B, vol. 70, pp. 115319, 2004.

(7) M. J. Gilbert and D. K. Ferry, "Efficient quantum three-dimensional modeling of fully depleted ballistic silicon-on-insulator metal-oxidesemiconductor field-effect-transistors," J. Appl. Phys., vol. 95, pp. 7954-7960, 2004.

(8) R. Venugopal, M. Paulsson, S. Goasguen, S. Datta, and M. S. Lundstrom, "A simple quantum mechanical treatment of scattering in nanoscale transistors," J. Appl. Phys., vol. 93, pp. 5613-5625, 2003.

(9) M. Bescond, K. Nehari, J. L. Autran, N. Cavassilas, D. Munteanu, and M. Lannoo, "3D quantum modeling and simulation of multiple-gate nanowire MOSFETs," IEDM Tech. Dig., pp. 617-620, 2004.

(10) A. Svizhenko, M. P. Anantram, T. R. Govindan, B. Biegel, and R. Venugopal, "Two-dimensional quantum mechanical modeling of nanotransistors," J. Appl. Phys., vol. 91, pp. 2343-2354, 2002.

(11) H. Khan, D. Mamaluy, and D. Vasileska, "Self-consistent treatment of quantum transport in 10-nm FinFET devices using CBR method," in Proc. IWCE 2006, J. Comput. Elec., in press.

(12) J. Seonghoon, P. Young June, and M. Hong Shick, "A threedimensional simulation of quantum transport in silicon nanowire transistor in the presence of electron-phonon interactions," J. Appl. Phys., vol. 99, pp. 123719, 2006.

(13) C. Jacoboni, R. Brunetti, P. Bordone, and A. Bertoni, "Quantum transport and its simulation with the Wigner-function approach," International Journal of High Speed Electronics and Systems, vol. 11, pp. 387-423, 2001.

(14) J. Saint-Martin, A. Bournel, F. Monsef, C. Chassat, and P. Dollfus, "Multi sub-band Monte Carlo simulation of an ultra-thin double gate MOSFET with 2D electron gas," Semicond. Science Technology, vol. 21, pp. L29-L31, 2006.

(15) L. Lucci, P. Palestri, D. Esseni, and L. Selmi, "Multi-subband monte carlo modeling of nano-mosfets with strong vertical quantization and electron gas degeneration," IEDM Tech. Dig., pp. 617-620, 2005.

(16) M. V. Fischetti and S. E. Laux, "Monte Carlo study of electron transport in silicon inversion layers," Phys. Rev. B, vol. 48, pp. 2244, 1993.

(17) V.-N. Do, P. Dollfus, and V.-L. Nguyen, "Shot Noise in Resonant Tunneling Structures Using Non Equilibrium Green's Function Calculation," in Proc. IWCE 2006, J. Comput. Elec., in press.

(18) J. Saint Martin, A. Bournel, and P. Dollfus, "On the ballistic transport in nanometer-scaled DG MOSFETs," IEEE Trans. Electron Devices, vol. 51, pp. 1148-1155, 2004. 